\title{
Ponded craters on Vesta
}

R. Parekh(1,2), K.A. Otto (1), R. Jaumann(2), K.D. Matz(1), T. Roatsch(1), E. Kersten(1), S. Elgner(1), K. Krohn(1), C. Raymond(3)

(1) DLR Institute of Planetary Research, Berlin, Germany, (2) Freie University of Berlin, Germany, (3) Jet Propulsion

Laboratory, California, USA. (rutu.parekh@dlr.de)

\section{Abstract}

Ponded craters have been predominantly identified on small, dry planetary bodies like (433) Eros and Itokawa. We identified similar features on Vesta, where loose fragmented ponded materials are present on small crater floors. While the morphological details of the ponded features on Vesta and Eros/Itokawa are similar, their production mechanisms may vary, due to differences in gravity or the insolation environment Previous studies conducted on Vesta have provided evidence for volatile outgassing in some regions. In this study, we investigate the morphology of the ponded crater and possible involvement of volatiles outgassing and its interaction with surface material in producing ponded craters on Vesta.

\section{Introduction}

Ponded craters have widely received lime light due to its unusual characteristics on Eros revealed by the NEAR Shoemaker mission (Sears et al., 2015, Robinson et al., 2001,2002). In general, ponded craters show a smooth layer of fine-grained material with grain size less then cm (Robinson et al., 2001) partially covering topography of the crater floor (Figure 1). They may also possess varying sized boulders or unconsolidated material (Sears et al., 2015). The depth of the pond is about $\sim 5 \%$ of the depth of the original crater (Robinson et al., 2001) on Eros. Other than the distinct morphological impression (smooth and flat floor), ponded crater regolith also shows sharp variation in the spectral signature (Robinson et al., 2001) which can be due to mineral heterogeneity (Robinson et al., 2001), space weathering (Sears et al., 2015, Heldmann et al., 2010, Robinson et al., 2001) or the difference in grain size between regolith and the surrounding region (Heldmann et al., 2010, Robinson et al., 2001).
Based on the evidences on Eros, the formation mechanisms of ponded craters include electrostatic levitation, seismic shaking and/or boulder comminution (Robinson et al., 2001). However, the effects of these mechanisms may vary on other dry planetary bodies with different compositions, gravity or insolation intensity. In our study, we characterize ponded craters on Vesta to understand their formation mechanisms and how interactions with the regolith may have influenced the generation of

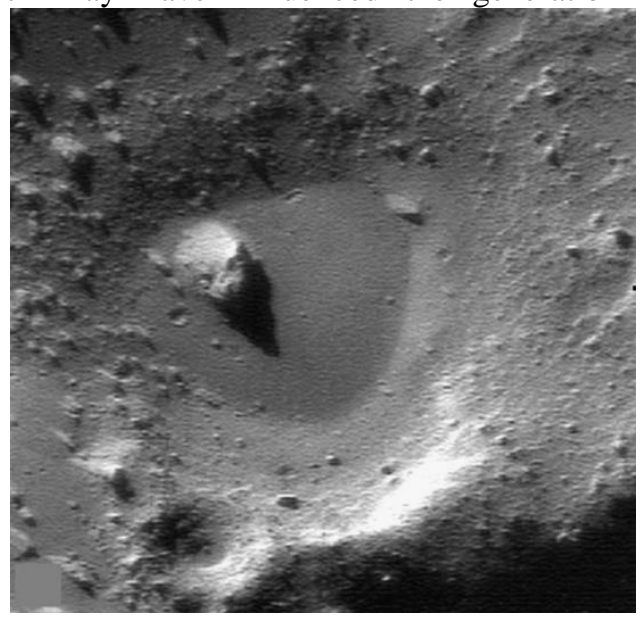

Figure 1: A classic example of pond crater on Eros. The crater has diameter of $\sim 0.09 \mathrm{~km}$ (Robinson et al., 2001). The pond material has sharp boundary, low albedo and flat smooth surface which makes it easy to distinguish from the original carter floor. Image source: Robinson et al., 2001

ponded craters.

\section{Data}

For the identification of ponded craters on Vesta, HAMO mosaics ( $70 \mathrm{~m} / \mathrm{pixel})$ and LAMO mosaics ( $20 \mathrm{~m} / \mathrm{pixel})$ provided by the NASA Dawn Mission were considered. To extract elevation information, a 
DTM of HAMO resolution was used $(92 \mathrm{~m} / \mathrm{pixel})$ (Preusker et al., 2016) prepared from stereo-pairs.

\section{Results}

So far, we have identified 10 ponded craters nearby the equator $\left(0^{\circ}-30^{\circ}\right)$ on Vesta. Overall, the crater floor is fully or partially covered by fine and loose material. The usual diameter of ponds ranges from $0.9-6.4 \mathrm{~km}$ within craters of $1.78-8.43 \mathrm{~km}$ diameter. Most of the identified ponded craters, have clear flat floors in which the fine material is evenly distributed within the bowl-shaped depression (Figure 1) covering the original floor of the crater entirely. An example is given in Figure 2, located at $15^{\circ} \mathrm{S}, 189^{\circ} \mathrm{E}$. The carter has a diameter of $\sim 8 \mathrm{~km}$. By fitting a polynomial shape (e.g. a parabola) to the crater walls, we estimated the original depth of the crater with $\sim 0.66 \mathrm{~km}$. The ponded material has filled the original crater surface, producing a shallow depth crater. The material has filled $\sim 0.31 \mathrm{~km}$ of the crater, which means half of the original crater depth is infilled by the fine material. On Eros ponds have average infilling depths of $\sim 10 \mathrm{~cm}$ or $5 \%$ of the original depth (Robinson et al., 2001). The smaller infilling might be due to the fact that craters on Eros are significantly smaller in comparison with Vesta. However, it is unreasonable to draw any conclusions based on a single example. At the meeting we will present measurements of the rest of the identified ponded sites to understand the overall morphology and discuss formation mechanisms for ponds on Vesta based on our findings.

\section{References}

[1] Heldamann et al., 2010, Icarus, 206, 685-690. [2] Robinson et al., 2001, Nature, 413,396-400. [3] Robinson et al., 2002, Meteorit. Planet. Sci., 37 1651-1684. [4] Sears et al., 2015, PSS, 117, 106-118.

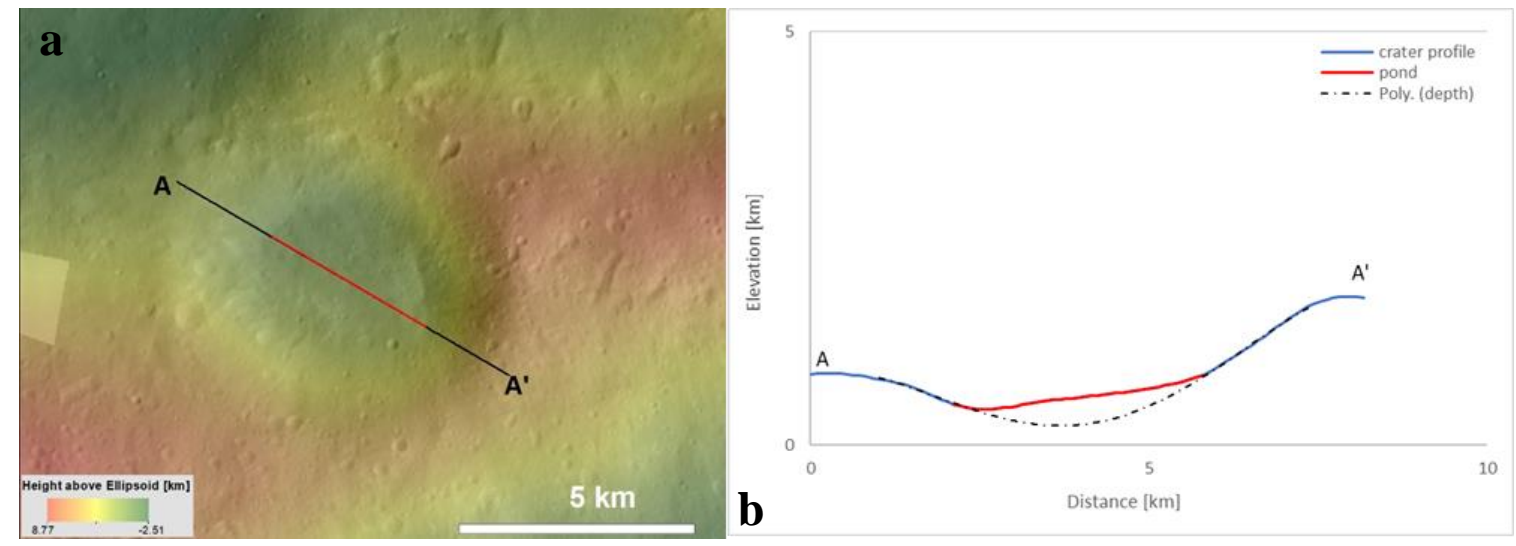

Figure 2: Example of a ponded crater on Vesta. (a) The ponded material is covering the original surface within central crater region and exhibits a flat and smooth texture. (b) The elevation profile of the crater in (a) highlighting the flat ponded material in red. The ponded material infilled the deeper parts of the crater depression, masking the original shape (dashdotted line) and generating a flat floor. 